\title{
Oligopeptides hydrolysed by muscle dipeptidyl peptidases can generate angiotensin-I converting enzyme inhibitory dipeptides
}

Miguel Ángel Sentandreu • Fidel Toldrá

Published online: 15 August 2006

(C) Springer-Verlag 2006

\section{Eur Food Res Technol (2006) s00217-006-0367-0}

Unfortunately, Table was published with errors. The correct table is given here:

Table $3 \mathrm{IC}_{50}$ values of dipeptides generated by the action of muscle DPP on the assayed substrates

\begin{tabular}{lc}
\hline Peptide & $\mathrm{IC}_{50}{ }^{\mathrm{a}}(\mu \mathrm{M})$ \\
\hline Gly-Gly & $3450.4 \pm 208.4$ \\
Ala-Gly & $1020.2 \pm 85.2$ \\
Phe-Gly & $515.7 \pm 0.30$ \\
Arg-Gly & $362.2 \pm 14.6$ \\
Tyr-Gly & $330.0 \pm 20.6$ \\
Val-Gly & $149.2 \pm 5.7$ \\
Met-Ala & $152.0 \pm 5.2$ \\
Arg-Phe & $136.7 \pm 5.4$ \\
Gly-Phe & $117.1 \pm 2.8$ \\
Arg-Ser & $61.5 \pm 5.9$ \\
Val-Tyr & $4.6 \pm 0.2$ \\
\hline
\end{tabular}

Results expressed as the mean of three replicates \pm standard deviation.

${ }^{a}$ The concentration inhibiting $50 \%$ of angiotensin-I converting enzyme activity, determined as described in materials and methods.

The online version of the original article can be found at http://dx.doi.org/10.1007/s00217-006-0367-0.

M. Á. Sentandreu $(\bowtie) \cdot$ F. Toldrá Instituto de Agroquímica y Tecnología de Alimentos (CSIC),

P.O. Box 73, 46100 Burjassot, Valencia, Spain

e-mail: ciesen@iata.csic.es

Fax: + 34-3636301 